\title{
Chilling-Requirement Release of Seed and Bud Dormancy in Apricot
}

\author{
Samir A. Seif El-Yazal ${ }^{1}$ and Mohamed A. El-Yazal, M.A. ${ }^{2}$ \\ ${ }^{1}$ Horticulture Department, Faculty of Agriculture, Fayoum University, Fayoum 63514, Egypt. \\ ${ }^{2}$ Botany Department, Faculty of Agriculture, Fayoum University, Fayoum 63514, Egypt.
}

Correspondence: sas00@fayoum.edu.eg

\begin{abstract}
Keywords: apricot (Prunus armeniaca L.), dormancy, stratification, germination, chilling requirements.
\end{abstract}

\begin{abstract}
Dormancy shows common physiological features in buds and seeds. Specific period of chilling is usually required to release dormancy. Reproductive meristems and embryos display dormancy mechanisms in specialized structures named respectively buds and seeds that arrest the growth of perennial plants until environmental conditions are optimal for survival. Chilling requirements for breaking dormancy were studied for 3 successive years in 20 seedling apricot trees which spanned the range of flowering times in these trees. Different methods for estimating chilling requirements were evaluated and compared, and correlations between chilling requirements and flowering date were established. The trees examined showed a range of chilling requirements, chill hours $(\mathrm{CH})$ between $199 \mathrm{CH}$ and $274 \mathrm{CH}$, and chill units, $(\mathrm{CU})$, between $612 \mathrm{CU}$ and 873CU. The results obtained in different years by the Utah and Dynamic models were more homogeneous with respect to the hours below $7{ }^{\circ} \mathrm{C}$ model. The apricot trees showed important differences concerning flowering date, and the results indicate a high positive correlation between chilling requirements and flowering date.Moreover, a specific low-temperature stratification treatment was required to overcome seed dormancy. $5^{\circ} \mathrm{C}$ cold stratification was found to be the best for breaking seed dormancy and germination. Increased seed germination percentage was recorded when the period of stratification prolonged. Apricot seeds required a cold stratification of about 12-15 days to reach maximum germination.
\end{abstract}

\section{Introduction}

The majority of trees in temperate climates fulfills a chilling demand (CR) in so as to overcome endodormancy and has a requirement of heat for flowering [1]. Chilling Hours $(\mathrm{CH})$ is that the easiest way to estimate chilling requirement. It is measured as the accumulated quantity of hours with temperatures $45^{\circ} \mathrm{F}\left(7.2^{\circ} \mathrm{C}\right)$ or lower throughout an industry designated time period (also in the study area November $1^{\text {st }}$ to March $\left.30^{\text {th }}\right)[2,3,4,5,6]$. Therefore, the CR could dissent by species, varieties, or growing regions $[7,8,9,10,11]$. CR is one the major issue that determines the bloom date $[12,13]$. Cultivars with low CR bloom and ripen earlier, whereas those with high CR bloom and ripen later $[14,15]$. CR constrains the acceptable areas of cultivation of the various commercially important tree species and cultivars around the world. Previous studies have indicated that CR might be quantitative character controlled by minimum of one major sequence $[16,17,18,19,20]$.

Seeds of stone fruits do not germinate immediately after harvest and a period of after ripening is essential for certain chemical and other changes to take place in the seed and for dormant embryo to grow [21,22,23]. Seed dormancy is a physiological phenomenon in plants, which is caused by external or internal factors, and prevent of seeds germination, even in optimal conditions. Seed dormancy may be caused due to hard seed coat, immature embryo, rudimentary embryo and inhibitors materials [23,24]. Seeds of temperate fruit species need a long time to germinate as a result of their requirement of stratification or cold treatment $[21,23,25]$. Seeds of temperate fruit species do not germinate as a result of seed dormancy even if conditions such as water, temperature, and oxygen are suitable for germination. Seed dormancy is classified as physiological, 
morphological, morpho-physiological, physical, and combinational dormancy (physical and physiological) [26,27]. Various methods have been tried to overcome dormancy of stone fruits. Stratification has been used traditionally to break seed dormancy in Prunus sp. [23,24,27]. Scarification can be done either mechanically or chemically[24].

The beneficial effect of stratification on seed germination were studied by $[22,23,28,29,30]$.

\section{Materials and Methods}

Twenty apricot seedling trees about 15-year-old were designated willy-nilly, for a preliminary study in 1996/1997/1998. All trees were full-grown within the wood let (newly reclaimed saline chalky soil) of the Horticultural Station at Abshawai, Fayoum, Egypt. For the most three seasons study, designated trees of every selection $(n=1)$ were tagged in November 1996, 1997and 1998and sampled from September-March,1997/1998,1998/1999and1999/2000.Every tree was designed together replicate, and every selection enclosed twenty trees (total $n=20$ ).

\section{Quantification of chilling requirements}

In this study, from Nov to March of next year, apricot branches from every selection were collected each fifteen days and cultivated in artificial lighting setup with water to see the bud dormancy emotional time (50\% bud break). Moreover, the quantity of chilling hours (temperatures between 0 and $7.2{ }^{\circ} \mathrm{C}$ ) throughout this period till the time of gap buds in every variety has been calculated (by using Thermograph). The foremost common chilling model, and one that is used wide, is that the Chilling Hours Model, additionally referred to as the Weinberger Model [31,32]. This model, that was $1^{\text {st }}$ developed for peaches in Georgia (United States), interprets all hours with temperatures between 0 and $7.2^{\circ} \mathrm{C}$ as effective for chilling accumulation. These Chilling Hours are accumulated through the winter season. Chilling hour's below $7.2^{\circ} \mathrm{C}$ from $1^{\text {st }}$ November to every opining date in apricot trees beneath study throughout each 1997/1998,1998/1999and1999/2000 seasons had been determined .Also chilling unites were calculated using the methods of [33].

Mature seeds of twenty seedling apricot trees were obtained at harvest time during 1998 and 1999 seasons from bearing trees grown in private orchard at Ibshawai district, Fayoum governorate, Egypt. The seeds were washed carefully with tap water and air dried. Hard shell (endocarp) of seeds were removed then subjected to the following treatments.

\section{Effect of cold stratification period on the germination of dormant apricot seeds:}

In both seasons, the seeds with removed endocarp were stratified at $5^{\circ} \mathrm{C}$ in moist sand until the embryonic root started to push through the seed of about $25 \%$ of the seeds. At three days intervals from each tree, samples of 3 replicates, each of 20 seeds were placed in 150x15mm petri dishes lined with two layers of Whatman No.2 filter paper moistened with a 200ppm solution of streptomycin sulfate. A single layer of filter paper moistened with streptomycin sulfate covered the seeds. Dishes were placed at $25^{\circ} \mathrm{C}$ in incubators to allow germination. The germination\% was calculated at three days interval during a period of 15 days.

The values presented in the results obtained in the (Table 3) is the mean of the three seasons under the study

\section{Statistical analysis:}

The Statistical analysis used in chilling requirements calculation was the coefficient of variation (CV) calculated from the data of chilling requirements (hours under $+7^{0} \mathrm{c}$ or chilling unites of each of twenty apricot seedling trees in the three successive seasons 1997/1998,1998/1999and1999/2000.The method that generally resulted in the lost CV was evaluated as the most suitable one 
All studied treatments were arranged in a complete randomized block design with three replicates for each and were statistically analyzed according to the method of [34].

\section{Results}

\section{1-Impact of winter chilling hours on bloom date}

To confirm however the winter accumulated chilling hours affected the spring events; we tend to investigate the total bloom date once completely different numbers of controlled chilling hours. Data in Table (1) clearly show that the dormancy releasing time of twenty seedling apricot trees show a great variation in chilling requirements the lowest chilling requirements trees were P-E-1-1 release from dormancy only after the accumulation of $199(\mathrm{CH})$ or 612 chill unites. On the other hand the highest chilling requirements trees were P-E-1-38 release from dormancy only after the accumulation of $274(\mathrm{CH})$ or 873 to satisfy the winter chilling requirement among the above the mentioned trees. There was a very high positive correlation between chilling requirement as hours under 7C and as chilling unites for twenty seedling apricot trees which were calculated. Also a strong positive correlation (Table 2)between the different studied winters in chilling requirement as hours under 7Cor chilling unites were observed.

Table (1): Chilling requirements (number of hours under $+7^{0} \mathrm{c}$ and chill unites) and Flowering of twenty apricot seedling trees, the data represent the mean of the three winter seasons

\begin{tabular}{|c|c|c|c|c|c|}
\hline \multirow{2}{*}{$\begin{array}{l}\text { Seedling } \\
\text { trees }\end{array}$} & \multicolumn{4}{|c|}{ Chilling requirements } & \multirow{2}{*}{$\begin{array}{c}\begin{array}{c}\text { Flowering } \\
\text { (days after }\end{array} \\
10 \text { February) }\end{array}$} \\
\hline & $\begin{array}{l}\text { Hours under } \\
\quad+7^{0} \mathrm{c}\end{array}$ & $\mathrm{CV}^{\mathrm{Z}}$ & Chill unites & $\mathrm{CV}^{\mathrm{Z}}$ & \\
\hline P-E-1-1 & 199 & 15.7 & 612 & 5.3 & 2 \\
\hline P-E-1-6 & 220 & 14.0 & 705 & 2.6 & 7 \\
\hline P-E -1-4 & 223 & 16.3 & 723 & 4.9 & 6 \\
\hline P-E -1-12 & 225 & 15.5 & 733 & 1.6 & 7 \\
\hline P-E -1-19 & 227 & 15.9 & 739 & 1.1 & 6 \\
\hline P-E-1-21 & 237 & 14.9 & 789 & 1.6 & 14 \\
\hline P-E-1-2 & 240 & 14.0 & 790 & 1.6 & 15 \\
\hline P-E-1-9 & 240 & 15.4 & 789 & 1.1 & 14 \\
\hline P-E-1-5 & 241 & 13.6 & 794 & 1.2 & 14 \\
\hline P-E-1-34 & 242 & 13.2 & 794 & 1.6 & 14 \\
\hline P-E-1-11 & 243 & 12.4 & 795 & 4.0 & 15 \\
\hline P-E-1-16 & 243 & 12.6 & 798 & 1.6 & 14 \\
\hline P-E-1-14 & 263 & 9.6 & 853 & 2.4 & 21 \\
\hline P-E-1-20 & 263 & 12.0 & 858 & 4.1 & 21 \\
\hline P-E-1-26 & 265 & 12.0 & 869 & 4.2 & 19 \\
\hline P-E-1-27 & 267 & 11.7 & 871 & 4.3 & 19 \\
\hline P-E-1-3 & 268 & 10.6 & 870 & 3.8 & 21 \\
\hline P-E-1-31 & 269 & 11.1 & 870 & 3.9 & 21 \\
\hline P-E-1-36 & 269 & 10.2 & 870 & 3.6 & 21 \\
\hline P-E-1-38 & 274 & 9.6 & 873 & 4.4 & 22 \\
\hline
\end{tabular}

$\mathrm{CV}=$ co-efficient of variation

Table (2): The relationship between the different winters in chilling requirements (number of hours under $+7^{0} \mathrm{c}$ and chill unites) for twenty apricot seedling trees

\begin{tabular}{|l|c|c|}
\hline Winters & \multicolumn{2}{|c|}{ Correlation Co-efficient } \\
\hline $1997 / 1998-1998 / 1999$ & $0.954^{\mathrm{xx}}$ & $0.914^{\mathrm{xx}}$ \\
\hline $1997 / 1998-1999 / 2000$ & $0.910^{\mathrm{xx}}$ & $0.982^{\mathrm{xx}}$ \\
\hline $1998 / 1999-1999 / 2000$ & $0.951^{\mathrm{xx}}$ & $0.957^{\mathrm{xx}}$ \\
\hline
\end{tabular}

$\mathrm{xx}$ highly significant Correlation Co-efficient 


\section{2-Flowering date}

With the buildup of low temperature, the chilling demand for fruit trees was step by step happy. Once the surroundings was appropriate, the bud would open. However, if the surroundings temperature was high, buds couldn't open, that was known as endodormancy. Data in Table (1) indicated that, the main flowering date (days after 10February) of the twenty apricot seedling trees ranging from day 2 for tree(P-E-1-1) to day 22 for tree P-E-1-35. Very late flowering trees tend to have high chilling requirements and early flowering trees tend to have low chilling requirements. In addition, a very high correlation between flowering date and chilling requirements as accumulated as chilling unite $\left(r=0.957^{\mathrm{xx}}\right)$ or as sum of hours under $+7 \mathrm{c}\left(\mathrm{r}=0.966^{\mathrm{xx}}\right)$ was obtained.

\section{3-Seed germination}

Data in Table(3) indicated that seed germination percentage in seedling apricot trees was significantly increased (after 15 days germination at $25{ }^{\circ} \mathrm{C}$ ) to $93 \%$ and $95 \%$ in 1998 and 1999 seasons respectively as compared to the control(non-stratified seeds).

Table (3): Effect of cold stratification period on germination\% of apricot seeds

\begin{tabular}{|c|c|c|r|r|c|c|c|c|c|c|}
\hline \multirow{2}{*}{$\begin{array}{c}\text { Stratification } \\
\text { period(days) } \\
\text { at } 5{ }^{\circ} \mathrm{C}\end{array}$} & \multicolumn{9}{|c|}{ Germination period (days) at $25^{\circ} \mathrm{C}$ in seedling apricot trees } \\
\cline { 2 - 11 } & $\mathbf{3}$ & $\mathbf{6}$ & $\mathbf{9}$ & $\mathbf{1 2}$ & 15 & $\mathbf{3}$ & 6 & 9 & 12 & $\mathbf{1 5}$ \\
\hline & $\begin{array}{c}\mathbf{3}) \\
8.11 \mathrm{~d}\end{array}$ & $11.0 \mathrm{~d}$ & $13.0 \mathrm{~d}$ & $14.0 \mathrm{~d}$ & $22.0 \mathrm{~d}$ & $\begin{array}{c}\mathrm{Z}) \\
7.0 \mathrm{~d}\end{array}$ & $9.0 \mathrm{c}$ & $15.0 \mathrm{c}$ & $13.0 \mathrm{c}$ & $20.0 \mathrm{~d}$ \\
\hline 3 & $6.0 \mathrm{~d}$ & $7.0 \mathrm{~d}$ & $8.0 \mathrm{e}$ & $11.0 \mathrm{e}$ & $14.0 \mathrm{e}$ & $5.0 \mathrm{~d}$ & $8.0 \mathrm{c}$ & $10.0 \mathrm{c}$ & $10.0 \mathrm{c}$ & $14.0 \mathrm{e}$ \\
\hline 6 & $3.0 \mathrm{e}$ & $5.0 \mathrm{e}$ & $7.0 \mathrm{e}$ & $8.0 \mathrm{e}$ & $11.0 \mathrm{e}$ & $3.0 \mathrm{e}$ & $5.0 \mathrm{e}$ & $6.0 \mathrm{e}$ & $7.0 \mathrm{e}$ & $12.0 \mathrm{e}$ \\
\hline 9 & $16.5 \mathrm{c}$ & $200 \mathrm{c}$ & $36.0 \mathrm{c}$ & $39.0 \mathrm{c}$ & $46.0 \mathrm{c}$ & $17.0 \mathrm{c}$ & $29.0 \mathrm{~b}$ & $33.0 \mathrm{~b}$ & $41.0 \mathrm{~b}$ & $44.0 \mathrm{c}$ \\
\hline 12 & $33.0 \mathrm{~b}$ & $380 \mathrm{~b}$ & $45.0 \mathrm{~b}$ & $50.0 \mathrm{~b}$ & $61.0 \mathrm{~b}$ & $35.0 \mathrm{~b}$ & $35.0 \mathrm{~b}$ & $39.0 \mathrm{~b}$ & $51 . \mathrm{b}$ & $63.0 \mathrm{~b}$ \\
\hline $15^{*}$ & $52.0 \mathrm{a}$ & $810 \mathrm{a}$ & $89.0 \mathrm{a}$ & $91.0 \mathrm{a}$ & $93.0 \mathrm{a}$ & $56.0 \mathrm{a}$ & $77.0 \mathrm{a}$ & $81.0 \mathrm{a}$ & $92.0 \mathrm{a}$ & $95.0 \mathrm{a}$ \\
\hline
\end{tabular}

The seeds of seedling apricot trees started to germinate during stratification $(\mathrm{Z})$

Mean separation, within columns, by Duncan's multiple range test, $5 \%$ level

The data also show that cold stratification at $5{ }^{\circ} \mathrm{C}$ had a stimulating effect on seed germination. Moreover, the number of days required for seed germination was decreased with the increase of cold stratification period (Table 3).

\section{Discussion}

It is clear nowadays that low temperature accumulation in dormancy stage was indispensable to bud break for deciduous fruit trees. Such models as (chilling hours below $7.2^{\circ} \mathrm{C}$ ) model, was the foremost dormancy cathartic model [32], and their accuracy for decisive the dormancy cathartic time was possibly influenced by specific environmental conditions because of lacking of the idea of physiological methodology. Winter chilling is associate agro environmental condition issue that integrates the length of cold periods also as prevailing temperature ranges. The presented results also show that buds of apricot seedling trees varied in their chilling requirements. If chilling wants don't appear to be met, irregular, delayed and asynchronous growth, flowering and fruit set are discovered inside the subsequent season [35,36,37,38]. The data also show that very late flowering trees tend to have high chilling requirements and early flowering trees tend to have low chilling requirements. One in all probability impact of temperature change can be a delay inside the beginning of chill accumulation; the fulfillment of chilling wants and then the time at those trees 
become receptive to heat through spring. Since flower and leaf emergence result from a minimum of part consecutive fulfillments of cold ('chilling') and warm ('forcing') wants, later and slower chilling accumulation should thus end in later flower and growth in spring[39,40,41].Apricot seeds are dormant and that dormancy breaking treatments have to be performed to obtain high germination and that the dormancy being caused by the permeability of the seed coat and fruit pericarp rather than by the embryo[42]. It is clear from the data that cold stratification at $5{ }^{\circ} \mathrm{C}$ had a stimulating effect on seed germination. In this respect,[43] reported that embryonic dormancy is defined as a set of blocks imposed upon a process(es) cardinal for growth. Also,[44] indicated that the elimination of embryonic dormancy in apple seeds was connected with a change from domination of PPP to domination of glycolysis in sugar catabolism during cold stratification. The presented results also show that apricot seedling trees varied in their stratification requirements. In this respect,[45] reported that apple seed germination depended on the cultivar and the manner of stratification. Among the examined cultivars, 'Szampion' seeds germinated at the highest percentage. Lower seed germination was observed for 'Ligol', whereas 'Gold Milenium' seeds germinated at the lowest percentage. The lowest germinability of 'Gold Milenium' seeds could be partly caused by a negative influence of germination inhibitors present in apple fruit extracts, that is, abscisic acids, chlorogenic acids, and so on[46,47] . In turn, the lower percentage of 'Ligol' seeds' germination may probably be caused due to their insufficient maturity. Obviously, the differences in their germinability may also depend on cultivar properties. Also, the percentage of seed germination depended not only on cultivar but also on the year of seed harvest [48]. The present study showed that stratification in water resulted in an increase of percentage of germinated seeds in comparison to control (untreated) seeds.

\section{Conclusions}

Chilling requirements for breaking dormancy and correlations between chilling requirements and flowering date were studied for seedling apricot trees which spanned the range of flowering times in these trees. The trees examined showed a range of chilling requirements, chill hours $(\mathrm{CH})$ between $199 \mathrm{CH}$ and $274 \mathrm{CH}$, and chill units, (CU), between $612 \mathrm{CU}$ and 873CU. The apricot trees showed important differences concerning flowering date, and the results indicate a high positive correlation between chilling requirements and flowering date.Moreover, a specific low-temperature stratification treatment was required to overcome seed dormancy. $5^{\circ} \mathrm{C}$ cold stratification was found to be the best for breaking seed dormancy and germination. Increased seed germination percentage was recorded when the period of stratification prolonged. Apricot seeds required a cold stratification of about 12-15 days to reach maximum germination.

\section{Conflict of Interest}

The author declare no conflict of interest

\section{References}

[1] J.A.Campoy et al., The fulfillment of chilling requirements and the adaptation of apricot (Prunus armeniaca L.) in warm winter climates: An approach in Murcia (Spain) and the Western Cape (South Africa), European Journal of Agronomy 37(2012) 43-55.

[2] K.Glozer and J.A. Grant, Use of the dynamic model and chill portions to time chemical restbreaking treatments in 'Bing' sweet cherry, In C. C. A. Board (Ed.): University of California Cooperative Extension(2005).

[3] M.A.Seif El-Yazal, Effect of timing of mineral oil spraying on budburst and metabolic changes in "Barkhar" apple trees under conditions of inadequate winter chilling in Egypt, Horticult. Int. J. 3(2) (2019a) 67-75. DOI:10.15406/hij.2019.03.00114 
[4] M.A.Seif El-Yazal, Seasonal changes in soluble and non-soluble carbohydrates during and after dormancy release in early and late varieties of apple (Malus Sylvestris, Mill) trees, International Journal For Empirical Education and Research. 3(20) (2019b)1-18.

[5] M.A.Seif El-Yazal, Impact of chilling requirement on budburst, floral development and hormonal level in buds of early and late apple varieties (Malus sylvestris, Mill) under natural conditions, Journal of Horticulture and Plant Research. 8(2019c)1-11.

[6] M.A.Seif El-Yazal, Impact of Chilling Requirements on Metabolic Changes in Phenolic Compounds in Buds during and after Dormancy Releasing in early and late (Malussylvestris, Mill) Apple Varieties, International Letters of Natural Sciences. 81(2021) 13-22.

[7] L.R.Wang et al., Peach genetic diversity, origin, and evolution. In: Wang L R, Zhu G R, Fang W C, eds., Peach Genetic Resource in China, Chinese Agriculture Press, Beijing, China. (2012) 263. (in Chinese)

[8] L. Andreini et al., The relationship between xylem differentiation and dormancy evolution in apricot flower buds (Prunus armeniaca L.): the influence of environmental conditions in two Mediterranean areas, Trees 26(2012) 919-928.

[9] M.A. Seif El-Yazal et al., Changes in promoter and inhibitor substances during dormancy release in apple buds under foliar-applied dormancy-breaking agents, International Journal for Empirical Education and Research. 1 (4) (2018b)1-20.

[10] M.A. Seif El-Yazal et al., Metabolic changes in polyamines, phenylethylamine, and arginine during bud break in apple flower buds under foliar-applied dormancy-breaking, International Journal for Empirical Education and Research. 1 (2) (2018c) 1-18.

[11] M.A. Seif El-Yazal et al., Changes in metabolic processes during break dormancy in apple buds under foliar-applied garlic extract, International Journal for Empirical Education and Research. 1(4) (2018d) 36-58.

[12] N. Alburquerqueet al., Chilling and heat requirements of sweet cherry cultivars and the relationship between altitude and the probability of satisfying the chill requirements, Environmental and Experimental Botany. 64(2008) 162-170.

[13] M.A. Seif El-Yazal andS.A. Seif El-Yazal, Impact of chilling requirements on metabolic changes in nitrogenous compounds in buds during and after dormancy releasing in early and late (Malus sylvestris, Mill) apple varieties, Horticult. Int.J. 3(5) (2019)230-238.

[14] A.A. El- Shewy et al., ffect of some dormancy breaking components on blooming, fruit set, yield, yield components and physical and chemical properties of fruits of some apple cultivars.

A. Blooming and fruit set, Annals of Agric. Sci., Moshtohor. 37(4) (1999a) 2235 - 2246.

[15] M.A. Seif El-Yazal andS.A. Seif El-Yazal, Impact of foliar-applied dormancy-breaking agents on flowering behavior, yield, fruit quality and some chemical constituents of " Ein Shamer" apple trees, Innovare Journal of Agri. Sci. 9 (1) (2021a) 16-21.

[16] R.Hauagge and J.N.Cummins, Genetics of length of dormancy period in Malus vegetative buds, Journal of the American Society for Horticultural Science, 116 (1991) 121-126.

[17] A.A. El- Shewy et al.,Effect of some dormancy breaking components on blooming, fruit set, yield, yield components and physical and chemical properties of fruits of some apple cultivars. B-.Yield, yield components and physical and chemical properties of fruits, Annals of Agric. Sci., Moshtohor. 37(4) (1999b) 2247 - 2267.

[18] M.A. Seif El-Yazal and M.M. Rady, Changes in nitrogen and polyamines during breaking bud dormancy in "Anna" apple trees with foliar application some compounds, Scientia Horticulturae. 136(2012) 75-80. 
[19] M.A. Seif El-Yazal and M.M. Rady, Foliar-applied Dormex ${ }^{\text {TM }}$ or thiourea-enhanced proline and biogenic amine contents and hastened breaking bud dormancy in "Ain Shemer" apple trees, Trees. 27 (1) (2013) 161-169.

[20] M.A. Seif El-Yazal and M.M. Rady,Exogenous onion extract hastens bud break, positively alters enzyme activity, hormone, amino acids and phenol contents, and improves fruit quality in 'Anna' apple trees, Scientia Horticulturae. 169(2014) 154-160.

[21] B.Şan et al., An in vitro germination technique for some stone fruit species: the embryo isolated from cotyledons successfully germinated without cold pre-treatment of seeds, American Society for Horticultural Science 49(3) (2014)294-296.

[22] S.A. Seif El-Yazal and M.A. Seif El-Yazal, The control of seed dormancy and germination by low temperature treatments, Innovare Journal of Agri. Sci, 9 (1) (2021) 11-15.

[23] S.A. Seif El-Yazal, Impact of seed cold stratification on apricot germination and subsequent seedling growth as well as chemical constituents of seeds during stratification, Horticult. Int.J.,5(4) (2021) 151-157.

[24] S.R. Mousavi et al., A general overview on seed dormancy and methods of breaking It, Advances in Environmental Biology 5(10) (2011) 3333-3337.

[25] R.A. Shahet al., Effect of seed priming on peach, plum and apricot germination and subsequent seedling growth, Indian J. Hort. 70(4) (2013) 591-594.

[26] J.M. Baskin and C.C. Baskin, Classification system for seed dormancy Seed Sci. Res. (2004) 14116.

[27] W.E. Finch-Savage and G. Leubner-Metzger, Seed dormancy and the control of germination, New Phytol.171, (2006)501-523.

[28] C. Guo et al., Effect of temperature, light, and ltorage lime on the seed germination of Pinus bungeana Zucc. ex Endl.: The role of seed-covering layers and abscisic acid changes, Forests 11(2020)300; doi:10.3390/f11030300

[29] M. Seng and E.J. Cheong, Comparative study of various pretreatment on seed germination of Dalbergiacochinchinensis, Forest Science and Technology, 16(2) (2020) 68-74, DOI: 10.1080/21580103.2020.1758801

[30] A. Yan and Z.Chen, The control of seed dormancy and germination by temperature, light and nitrate, The Botanical Review 86(2020) 39-75.

[31] J.P. Bennett, Temperature and bud rest period, Calif Agric, 3 (11) (1949) 9-12.

[32] J.H. Weinberger, Chilling requirements of peach varieties. Proc Am Soc. Hortic. Sci., 56(1950) 122-128.

[33] S.A. Seif and W. Gruppe, Chilling requirements of sweet cherry (Prunus avium), and interspecific cherry hybrid (prunus X ssp), Acta Horticulturae 169(1985)106-112.

[34] D.B. Duncan, Multiple range and multiple F tests. Biometrics 11(1955) 1-42.

[35] E. Luedeling et al., Climate change effects on winter chill for fruit crops in GermanyAuswirkungen des Klimawandels auf die Verfügbarkeit von Kältewirkung (Chilling) für Obstgehölze in Deutschland, Erwerbs-Obstbau., 51(2009) 81-94. doi: 10.1007/s10341-0090085-4. [CrossRef]

[36] J.A. Campoy et al., Dormancy in temperate fruit trees in a global warming context: a review, Sci Hortic., 130(2) (2011) 357-372. doi: 10.1016/j.scienta.2011.07.011. [CrossRef] 
[37] M.A. Seif El-Yazal et al., Foliar-applied dormancy-breaking chemicals change the content of nitrogenous compounds in the buds of apple (Malus sylvestris Mill. cv. Anna) trees, Journal of Horticultural Science \& Biotechnology87(4) (2012) 299-304.

[38] M.A. Seif El-Yazal et al., Exogenous dormancy-breaking substances positively change endogenous phytohormones and amino acids during dormancy release in 'Anna' apple trees, Plant Growth Regul. 72(2014) 211-220.

[39] E. Luedeling et al., Identification of chilling and heat requirements of cherry trees-a statistical approaches, Int. J. Biometeorology, 57(5) (2013) 679-689.

[40] M.M. Rady and M.A. Seif El-Yazal, Response of "Anna" apple dormant buds and carbohydrate metabolism during floral bud break to onion extract, Scientia Horticulturae. 155(2013) 78-84.

[41] M.M. Rady and M.A. Seif El-Yazal, Garlic extract as a novel strategy to hasten dormancy release in buds of 'Anna' apple trees, South African Journal of Botany. 92(2014) 105-111.

[42] A. Eriş, Bahçe Bitkileri Fizyolojisi. U.Ü.Z.F. Ders Notları No: 11 (1990) 152s

[43] S. Lewak, Metabolic control of embryonic dormancy in apple seed: seven decades of research, Acta Physiologiae Plantarum 33 (2011) 1-24.

[44] R. Bogatek and S. Lewak, Effect of cyanide and cold treatment on sugar catabolism in apple seeds during dormancy removal, Physiol Plant 173 (1988) 406-411.

[45] K. Górnik et al., The Effect of Apple Seed Stratification with Growth Regulators on Breaking the Dormancy of Seeds, the Growth of Seedlings and Chlorophyll Fluorescence, Journal of Horticultural Research26(1) (2018)37-44.

[46] R. Rudnicki, Studies on abscisic acid in apple seeds, Planta 86 (1969) 63-68. DOI: $10.1007 / \mathrm{bf00385304.}$

[47] W. Kamiński, Inhibitory effect of apple juice on the germination of apple and cherry seeds and the growth of apple seedlings, Acta Societatis Botanicorum Poloniae 37(1) (1968) 173178. DOI: $10.5586 /$ asbp. 1968.016.

[48] J.D. Bewley and M. Black, Seeds. Physiology of development and germination. Plenum Press, New York, 445 (1994) DOI: 10.1007/978-1-4899-1002-8 